\title{
A APLICAÇÃO DO PRINCÍPIO DA INEXIGIBILIDADE DE CONDUTA DIVERSA EM TEMPOS DE CRISE ECONÔMICA
}

\section{THE APPLICATION OF THE PRINCIPLE OF UNENFORCEABILITY FOR DIVERSE CONDUCT IN TIMES OF ECONOMIC CRISIS}

\begin{abstract}
Alexandre Toneli ${ }^{1}$
RESUMO: A inexigibilidade de conduta adversa é uma causa geral de exclusão da culpabilidade elevada a princípio de direito, fundada na não censurabilidade de uma conduta e centrada numa situação anormal e insuportável, em que o agente se encontrava, pois, ao praticar uma ação que, impelida pela falta de alternativa, não pode ser considerada ilícita à luz da melhor interpretação ao sistema jurídico brasileiro.

Palavras-chave: princípio; inexigibilidade; conduta; adversa; exclusão.

ABSTRACT: The unenforceability of adverse conduct is a general cause of exclusion of elevated guilt by the principle of rights, founded in the non-objectionability of a conduct and centered in an abnormal and unbearable situation that the agent encountered. Therefore, when practicing a certain conduct that, impelled by the lack of an alternative, it cannot be considered illicit in the light of the best interpretation of the Brazilian juridical system.
\end{abstract}

Keywords: principle; unenforceable; conduct; adverse; exclusion.

\footnotetext{
1 Advogado e pós-graduado do Curso de Especialização "Lato Sensu" em Direito do Estado pela UNESA. E-mail: aletoneli@hotmail.com.
} 


\section{INTRODUÇÃO}

É forçoso reconhecer que o Direito Penal, como ciência, não pode deixar de se servir de dogmas. A tarefa da dogmática da ciência penal, voltada ao Direito vigente, é expor conceitualmente o conteúdo e a construção dos princípios jurídicos do Direito Penal.

Com raciocínio dogmático, por conseguinte,

a culpabilidade pode ser entendida como o conjunto de elementos psíquicos, anímicos e sociais expressados em um ato ilícito, compreendidos por um sistema penal, e que caracterizam o senso de reprovação que a sociedade exprime em relação ao autor da ação proibida. (VELO, 1993, p. 23)

Verifica-se que a lei prevê a inexistência de crime quando ocorre uma das causas que exclui a antijuridicidade. É necessário, porém, verificar se há culpabilidade para impor a pena ao agente que praticou o ilícito. A conclusão, portanto, é a de que mesmo o agente tendo praticado um crime (fato típico e antijurídico) estará isento da pena por ausência da reprovabilidade da conduta.

\section{TEORIAS}

São três as teorias a respeito da culpabilidade:
a) Teoria Psicológica;
b) Teoria Psicológica - Normativa; e
c) Teoria Normativa.

A Teoria Psicológica da culpabilidade foi a expressão das intenções liberais iluministas para fundamentar eticamente a punição, condicionando a responsabilidade penal à existência de uma relação psíquica entre o autor $\mathrm{e} o$ fato delituoso.

Assim, a teoria psicológica da culpabilidade corresponde à teoria clássica $e$ reside apenas na relação psíquica do autor com o fato. Esse conceito, puramente naturalístico e desprovido de juízo de valor, considera que há culpabilidade quando existir dolo ou culpa stricto sensu. Tal princípio é insuficiente, bastando assinalar que não existe um vínculo psicológico entre o agente e o resultado no crime culposo.

Essa teoria, no Direito Penal, apesar de sua influência, foi abandonada por não conseguir respostas adequadas para a culpa inconsciente e o estado de necessidade exculpante.

\section{A Teoria Psicológica - Normativa} corresponde à teoria social da ação, pressupõe a existência de elemento psicológico (dolo ou culpa), mas funda-se na reprovabilidade de conduta.

Destarte, foi o primeiro passo para superar as vulnerabilidades da teoria psicológica e Frank, em 1907, assinalou como elemento independente da culpabilidade junto ao dolo e à culpa, a motivação normal. Assim, o dolo e a culpa não esgotam a culpabilidade. Para ele, esta deve fundar-se em todos os elementos que influem sobre a valoração jurídica da ação e não só sobre a relação psicológica entre 0 autor e o resultado (COSTA, 1982, p. 750).

Diante disso, os elementos da culpabilidade seriam, pois:

a) a imputabilidade; 
b) 0 elemento psicológico normativo (dolo ou culpa); e

c) a exigibilidade de conduta diversa.

A posição de Frank traz uma modificação completa na análise dos elementos da culpabilidade, pois o dolo e a culpa não são espécies, apenas elementos integrantes do amplo conceito, transformando a culpabilidade num juízo de apreciação (COSTA, 1982, p. 751).

É insatisfatória a determinação dos elementos da culpabilidade formulados na teoria de Frank, que apresenta o dolo como elemento constitutivo da culpabilidade e o dolo não é um juízo de valoração, mas um fato psicológico. Não é um conceito normativo puro, mas complexo, integrado de fatos psicológicos e do juízo de valoração (COSTA, 1982, p. 751).

Mezger diz que "Culpabilidade é reprovabilidade e este conhecimento não é uma situação de fato psicológica, mas uma situação fática valorada normativamente, que se designa com o nome de concepção normativa da culpabilidade" (COSTA, 1982, p. 750$)$.

Por fim, a Teoria Normativa Pura corresponde aos ensinamentos da escola finalista, na qual se afirma que o dolo e a culpa não pertencem à culpabilidade, mas ao próprio fato típico, componentes que são da conduta. A culpabilidade cinge-se apenas a um juízo de reprovação pessoal pela perpetração de um fato lesivo de um interesse penalmente protegido. Seus elementos são:

a) a imputabilidade;

b) a possibilidade de conhecimento do injusto; $e$ c) a exigibilidade de conduta diversa.

Tais elementos constituem um juízo de valor excluído de qualquer fator psicológico, já que esse é objeto da estrutura do dolo e da culpa.

\section{ELEMENTOS DA CULPABILIDADE}

A imputabilidade penal, primeiro elemento da culpabilidade, é o conjunto de condições que dá ao agente a capacidade de ser juridicamente imputada a ele a prática de um fato punível. Exemplos que a excluem: a menoridade penal, embriaguez fortuita completa etc.

A possibilidade do conhecimento do injusto ou a potencial consciência da ilicitude, segundo elemento da culpabilidade, é melhor conceituada pela teoria extrema da culpabilidade (Escola Finalista). Só há culpabilidade quando 0 agente tem condições ou possibilidades de saber que pratica ato ilícito. A inexistência dessa possibilidade exclui a culpabilidade, embora subsista o dolo; o que não há é a reprovabilidade, a censurabilidade da conduta dolosa. Nessas condições, o erro de proibição não exclui o dolo, mas a culpabilidade, enquanto o erro de tipo exclui o próprio dolo.

A inexigibilidade de conduta diversa, terceiro elemento, é o que indica só haver culpabilidade quando, devendo e podendo agir de maneira conforme o direito, o agente pratica conduta diferente, que constitui o delito. "Não há reprovabilidade se na situação em que se achava o agente não lhe era exigível comportamento diverso" (MIRABETTE, 1986, p. 101).

A avaliação deve ser feita em função 
de um caso concreto, diante das circunstâncias concretas, com base nos padrões sociais vigentes.

Alguns autores entendem que a exigibilidade de conduta diversa não é uma causa geral (ou supralegal) de exclusão da culpabilidade, restringindo-se apenas aos casos expressos em lei.

Porém, outros autores admitem a exigibilidade de conduta diversa com causa supralegal de exclusão da culpabilidade, a ser aplicada de forma excepcional, mas de modo independente de previsão legal expressa.

\section{DIRIMENTES}

As dirimentes ou causas de exclusão da culpabilidade excluem a culpabilidade e, em consequência, excluem a pena, sem excluir, porém, a existência do crime.

Por isso, as dirimentes revelam-se geralmente pelas expressões "é isento de pena", "não é punível", entre outras. Estas excluem a culpabilidade pela inimputabilidade, pela impossibilidade de conhecimento do ilícito e pela inexigibilidade de conduta diversa.

De naturezas diversas, são as justificativas ou causas de exclusão de crime, pois não excluem somente a pena, mas o próprio crime. Assim, costuma a lei usar a expressão "não há crime".

Além das justificativas e dirimentes, existem ainda uns raros casos chamados de escusas absolutórias. As escusas absolutórias são causas pessoais que excluem a punibilidade, assemelhando-se às dirimentes. Só que não excluem o crime nem a culpabilidade, e sim a pena.

\section{INEXIGIBILIDADE DE CONDUTA DIVERSA}

\subsection{Conceito}

Considerando-se que a estrutura do conceito da culpabilidade é composta dos seguintes elementos: imputabilidade, potencial consciência da ilicitude e exigibilidade de outra conduta, não basta a prática de um fato típico e antijurídico, ou seja, de um crime, para que o agente fique sujeito à correspondente punição. É necessário que, por ocasião da conduta, seja ele imputável. Vale ressaltar, capaz de entender e de querer, com potencial consciência da ilicitude e, finalmente, que Ihe possa ser exigido nas circunstâncias outro comportamento.

Deflui, dessarte, a teoria esposada como causa de exclusão da culpabilidade pode ser aplicada tanto aos fatos dolosos como culposos. Admitir a inexigibilidade de outra conduta somente aos casos culposos significaria repudiá-la, pura e simplesmente.

Em situações excepcionais, a pessoa pode ver-se compelida a praticar determinada conduta, embora ciente de que seja ela contrária à lei. Entretanto, não ficando, não obstante, sujeito à punição, porque qualquer ser humano normal, nas mesmas condições, teria igual comportamento, sendo esse, assim, censurável.

Se a hipótese é regulada em lei, constata-se uma causa legal de exclusão da culpabilidade escudada no princípio da 
inexigibilidade de conduta diversa. Porém, a falta de previsão legislativa não impede que o mesmo princípio seja aplicado como causa geral e supralegal de exclusão da culpabilidade.

\subsection{Causas legais de exclusão da culpabilidade}

O Código Penal Brasileiro (1940) indica as seguintes causas legais da exclusão da culpabilidade:

a) Erro de Proibição (art. 21, caput);

b) Coação Moral Irresistível (art. 22, 1a parte);

c) Obediência Hierárquica (art. 22, 2ª parte);

d) Inimputabilidade (doença mental ou desenvolvimento mental incompleto ou retardado - art. 26, caput);

e) Inimputabilidade (menoridade penal, art. 27);

f) Inimputabilidade (embriaguez completa, proveniente de caso fortuito ou força maior - art. 28, parágrafo $1 \%$ ).

Essas causas estão relacionadas aos elementos da culpabilidade. Cada um exclui certo elemento e, em consequência, a causa legal fica excluída.

Portanto, o erro de proibição exclui a potencial consciência da ilicitude; a coação moral irresistível e a obediência hierárquica excluem e exigibilidade de conduta diversa; e a doença mental, o desenvolvimento mental incompleto ou retardado, a menoridade e a embriaguez fortuita completa excluem a imputabilidade penal.

\subsection{Posicionamentos doutrinários e jurisprudenciais}

Para os partidários do princípio da inexigibilidade de conduta diversa restrita aos casos estabelecidos em lei, destacamos Nelson Hungria, Heleno Cláudio Fragoso e Fernando de Almeida Pedroso.

O mestre Nelson Hungria combate com ardor:

Certa corrente de autores (Eb. Schimidt, Freudenthal, Mezger, Siegert), para suprir falha do Código Penal do seu país, entende que deva ser reconhecida como causa (supralegal) de exclusão de culpabilidade a 'não exigibilidade' (Nichtzumutbarkeit) e assim argumenta: se o pressuposto da culpabilidade (falta moral) é a censurabilidade (Vorwerfharkeit) da ação, segue-se que ela exprime a violação de um dever de conduta, do ponto de vista social; mas, conduta social não pode ser senão aquela que, sendo exigível de um indivíduo, não é seguida por este. $A$ censurabilidade deixa de existir quando o indivíduo falta à observância de uma conduta que se apresentava impraticável no caso concreto (ultra posse nemo tentaur) ou particularmente difícil, não exigível do homo medius, do comum dos homens. $O$ nosso Código assimilou explicitamente o critério da 'não-exigibilidade', mas para reconhecer, segundo a maior ou menor premência das circunstâncias, ora uma discriminante, isto é, identificando-a como a própria essência do 'estado 
de necessidade' (art.20, caput), ora simples minorante (art. 20, parágrafo $2^{\circ}$ ) (HUNGRIA, 19581, p. 26).

O ilustre Heleno Cláudio Fragoso aduz, "a inexigibilidade de outra conduta não funciona como causa supralegal de exclusão da culpabilidade, posto isto equivaleria ao abandono de todo o critério objetivo para a exclusão de reprovabilidade pessoal" (FRAGOSO, 1971, p. 140).

A propósito, o eminente professor Fernando de Almeida Pedroso também manifesta a sua posição:

Não comungamos do pensar de insignes penalistas que alargam em demasia os domínios da aferição da inexigibilidade de outra conduta, prescrutando-a sem bases legais fixadas e consoantes as circunstâncias que deram evolver ao episódio. Não procede, conforme nos afigura, erigir a inexigibilidade de outra conduta como forma genérica de exclusão da culpabilidade. $O$ elastério exagerado ou indiscriminado debilita a repressão, abrindo espaço para tergiversações à responsabilidade. Assim, a inexigibilidade de outro comportamento, por conseguinte, não deve ser examinado pelo normativismo puro, 'id est', com elasticidade e amplitude, cumprindo que se atrele e acrisole a situações específicas e explicitamente determinadas, insculpidas na lei como dirimentes (PEDROSO, 1993, p. 508).
Por outro flanco, a teoria da inexigibilidade de outra conduta não pode ficar somente aos casos estabelecidos em lei. Nesse diapasão, incluem-se Jiménez de Asúa, Aníbal Bruno, Alberto Silva Franco, Basileu Garcia, Celso Delmanto, Damásio Evangelista de Jesus, Francisco de Assis Toledo, José Henrique Pierangeli, Magalhães Noronha, Lydio Machado Bandeira de Mello e José Frederico Marques (CAMPOS, 1998, p. 44).

Por certo, apesar do excesso de propaganda oficial, o Estado não tem conseguido cumprir com suas funções básicas. Ocorre que, cada vez, as pessoas têm dificuldades para encontrar os recursos necessários à sua sobrevivência. E, diante disso, o Direito não pode exigir comportamento heróico, ou seja, toda norma jurídica tem um âmbito de exigência, fora do qual não se pode exigir responsabilidade alguma.

Traz-se à baila, então, a posição de Francisco de Assis Toledo:

A inexigibilidade de outra conduta é, pois, a primeira e mais importante causa de exclusão da culpabilidade. E constitui um verdadeiro princípio de direito penal. Quando aflora em preceitos legislados, é uma causa legal de exclusão. Se não, deve ser reputada causa supralegal, exigindo-se em princípio fundamental que está intimamente ligado com o problema da responsabilidade pessoal e que, todavia, dispensa a existência de normas expressas a respeito (TOLEDO, 1991, p. 328).

O ilustre José Frederico Marques 
assevera que "Não há porque deixar de admitir a exclusão da culpabilidade quando uma conduta típica ocorreu sob a pressão anormal de acontecimentos e circunstâncias que excluem o caráter reprovável dessa mesma conduta" (BITTENCOURT, 1998, p. 103).

Por derradeiro, se adotada a teoria normativa, não há culpabilidade todas as vezes em que, tendo em vista as circunstâncias do caso concreto, não se possa exigir do sujeito uma conduta diversa daquela por ele cometida. Até porque, por mais previdente que seja o legislador, ele não pode prever todos os casos em que a inexigibilidade de outra conduta deve excluir a culpabilidade.

Assim, é possível a existência de um fato não previsto pelo legislador como causa de exclusão da culpabilidade que apresente todos os requisitos do princípio da nãoexigibilidade de comportamento lícito. Em face de um caso concreto, seria condenar o sujeito unicamente porque 0 fato não foi previsto pelo legislador?

Se a conduta não é culpável, por ser inexigível outra, a punição seria injusta, pois não há pena sem culpa. Daí ser possível a adoção da teoria de inexigibilidade como causa supralegal de exclusão da culpabilidade (OLIVEIRA FILHO, 1996, p. 190).

No Brasil, quem mais se destacou no estudo da não-exigibilidade de outra conduta foi Souza Neto, no seu exaustivo estudo, demonstrou que o nosso Código Penal não se opõe à aplicação da teoria em comento, no âmbito da culpa ou dolo, porém, com mais cuidado nos casos dolosos.

O Professor Aníbal Bruno, ocupando- se do assunto, admite a teoria da inexigibilidade de outra conduta com o caráter de causa geral de exclusão da culpabilidade em qualquer das suas formas dolo ou culpa. Para o mestre pernambucano, tal princípio está realmente implícito no Código Penal e pode aplicar-se por analogia "in bonam partem" (MAGALHÃES, 1975, p. 42).

Para o mestre Bettiol:

Numa concepção normativa, a culpabilidade desaparece todas as vezes em que - dadas as condições do atuar - não se possa 'exigir' do sujeito agente um comportamento diverso daquele efetivamente adotado (BETTIOL, 1971, p. 140).

Cumpre registrar, que, no anteprojeto do Professor Nelson Hungria do Código Penal de 1962, que acabou por não vingar, este se ocupava da inexigibilidade de outra conduta.

A aplicação da teoria do princípio da inexigibilidade de conduta diversa como causa supralegal de exclusão da culpabilidade encontra apoio na integração da lei penal.

O Direito Penal Positivo possui lacunas. Havendo omissão legislativa no conjunto das normas penais não incriminadoras e não havendo o obstáculo do princípio da reserva legal, a falha pode ser suprida pelos processos determinados pelo artigo $4^{\circ}$ da Lei de Introdução ao Código Civil (LICC), isto é, analogia, os costumes e os princípios gerais de direito.

Portanto, caso não haja norma descritiva de fato semelhante, o juiz pode 
absolver o sujeito com base nos costumes e nos princípios gerais de direito em que se fundamentam a inexigibilidade. Assim, o juiz aplicaria uma causa supralegal de exclusão da culpabilidade.

Máxime, julgando improcedente a pretensão punitiva do Estado, com respaldo na analogia ou nas causas supralegais, pode o juiz fundamentar, com espeque no artigo 386, inciso VI, do Código de Processo Penal, o princípio da inexigibilidade de conduta diversa, a saber:

'O juiz absolverá o réu, mencionado a causa na parte dispositiva, desde que reconheça (caput):

VI - existirem circunstâncias que excluam o crime ou isentem o réu de pena (arts. 20, 21, 22, 23, 26 e $\S$ $1^{\circ}$ do art. 28, todos do Código Penal), ou mesmo se houver fundada dúvida sobre sua existência; (Redação dada ao inciso pela Lei no 11.690, de 09.06.2008, DOU 10.06.2008, com efeitos a partir de 60 (sessenta) dias após a data de sua publicação)'

Certamente, cortar a priori uma forma de inexigibilidade de outra conduta como causa de exclusão da culpabilidade, ou é supor que o legislador penal tem uma consciência que em outros setores do direito ninguém afirma existir, ou então considerar o direito penal uma espécie "sui generis" da ciência jurídica em que não há omissões nem lacunas. Verdadeira zona do universo jurídico, em que o sentido finalístico da norma jurídica, como imperativo das exigências sociais, deve ser de todo arriscado (OLIVEIRA FILHO, 1996, p. 130).

Recordamos o fato do sacoleiro, como regra, pertencer à base da pirâmide social e ter uma ocupação profissional que não lhe rende o necessário para viver (FERREIRA SOBRINHO, 1995, p. 370).

Surge, então, o angustiante problema representado pela incompetência do Estado em fornecer os meios necessários à subsistência material digna do seu povo, e nisso se inclui o problema do alto índice de desemprego (FERREIRA SOBRINNHO, 1995, p. 370).

Parece factível indagar se um cidadão sem trabalho e sem meios materiais para garantir sua subsistência deve aguardar sua morte física em razão da falta de ajuda estatal. Se o Estado não cumpre com sua finalidade primeira - o bem-estar da população - não pode querer punir alguém que, para viver, passa a vender mercadorias estrangeiras (FERREIRA SOBRINHO, 1995, p. 370). Ou, então, condenar cambistas.

Se, ao adotar esta última concepção, estar-se-á sustentando que um indivíduo sem representação econômica e sem trabalho, em um Estado ausente na regulação da distribuição adequada de renda e do mercado de trabalho, haverá de se conformar com tal situação ou, quem sabe, esperar a reversão do quadro desfavorável? (FERREIRA SOBRINHO, 1995, p. 371).

Diante do exposto, a hipótese aventada como inexigibilidade de outra conduta, é capaz, por isso mesmo, de excluir a culpabilidade penal (FERREIRA SOBRINHO, 1995, p. 371). 


\section{CRIMES CONTRA A ORDEM TRIBUTÁRIA}

Nesse alvitre, destacamos a aplicação do princípio da inexigibilidade de conduta diversa na seara do Direito Tributário, mais especificamente nos crimes contra a ordem tributária, estabelecido no artigo $1^{\circ}$ da Lei Federal $\mathrm{n}^{\circ}$ 8137/90, bem como na apropriação indébita inserido no artigo 168A do Código Penal.

Portanto, algumas decisões judiciais reconhecem a aplicação do princípio em comento nos momentos de dificuldades financeiras das empresas.

Nessa linha,

O empregador demonstra superlativa preocupação com os créditos de natureza trabalhista, em especial, pelos salários dos funcionários. Tal cuidado não é privilégio seu, mas sim, espelha pela preocupação geral de toda sociedade com a questão alimentícia. O legislador no Código Tributário Nacional firmou princípio ao dispor, em seu artigo 186, que o 'crédito tributário prefere a qualquer outro, seja qual for a natureza ou o tempo da constituição deste, ressalvados os créditos decorrentes da legislação do trabalho'. Assim, deve o magistrado observar tal paradigma e, uma vez que até mesmo o crédito trabalhista foi atingido pelas dificuldades financeiras da empresa no período denunciado, não se poderia exigir comportamento diverso do empregador, situação que exclui a reprovabilidade de sua conduta na hipótese de inadimplemento, eis que se pressupõem a ausência de numerário para saldar quaisquer outras obrigações, inclusive as tributárias. (ROSA, 1999, p. 247)

PENAL - PROCESSO PENAL EMBARGOS INFRINGENTES EM APELACCÃO CRIMINAL ACÓRDÃO QUE REFORMOU SENTENÇA ABSOLUTÓRIA CRIME DE APROPRIAÇÃO INDÉBITA PREVIDENCIÁRIA ARTIGO 168-A DO CÓDIGO PENAL - VOTO VENCIDO ACOLHIMENTO - REFORMA DO ACÓRDÃO - OCORRÊNCIA DIFICULDADES FINANCEIRAS INEXIGIBILIDADE DE CONDUTA DIVERSA - ABSOLVIÇÃO ARTIGO 386, VI DO CPP (REDAÇÃO DADA PELA LEI 11.690/2008) - MANUTENÇÃO DA DECISÃO MONOCRÁTICA - 1 Constitui apropriação indébita previdenciária deixar de repassar à Previdência Social as contribuições recolhidas dos contribuintes, no prazo e forma legal ou convencional (caput do Artigo 168-A do CP, acrescentado pela Lei no 9983/200 de 14.07.2000) 2- O dolo do delito é a vontade de não repassar à previdência as contribuições recolhidas, obedecendo ao prazo e à forma legal. Não se exige fim específico, ou seja, a animus rem si habendi, ao contrário do que ocorre na apropriação indébita comum. 3Resta caracterizada a inexigibilidade de conduta diversa em razão da crise financeira enfrentada pela empresa; 
Comprovada através de depoimentos das testemunhas e pela prova documental (existência de diversas ações executórias fiscais intentadas em desfavor dos acusados). 4- Embargos infringentes acolhidos e acórdão reformado, com prevalência do voto vencido, para negar provimento à apelação do MPF e confirmar a sentença absolutória, porém com esteio na atual redação dada, pela Lei no 11.690/2008, ao artigo 386, VI do Código de Processo Penal. (MOREIRA, 2009, p. 99)

PENAL E PROCESSUAL PENAL APELAÇÃO CRIMINAL NÃO RECOLHIMENTO DE CONTRIBUIÇÃO

PREVIDENCIÁRIA DESCONTADA

DE EMPREGADOS - ART. 168-A DO CÓDIGO PENAL BRASILEIRO - AUTORIA E MATERIALIDADE COMPROVADAS

DIFICULDADES FINANCEIRAS DEMONSTRADAS

INEXIGIBILIDADE DE CONDUTA DIVERSA - RECURSO MINISTERIAL IMPROVIDO - I- A comprovação de dificuldades financeiras, pela apresentação de documentação idônea, demonstra a impossibilidade de os apelados agirem conforme o direito, restando excluída a culpabilidade por inexigibilidade de conduta diversa, impondo-se a absolvição com fundamento no art. 386, $V$, do CPP. II- Apelo do Ministério Público Federal a que se NEGA PROV I M E N TO (AZULAY NETO, 2008, p. 123).

\section{CONCLUSÃO}

Com efeito, ficou demonstrado que, para a caracterização da culpabilidade de um agente, necessário se faz que lhe seja exigido em circunstâncias normais outro comportamento.

Ainda, foi constado que existem situações que fogem da normalidade cotidiana, necessitando, portanto, de uma atuação do Poder Judiciário, por intermédio da aplicação do princípio da inexigibilidade de conduta diversa, como causa de exclusão da culpabilidade, também nos casos em que a lei se faz omissa, apesar de algumas opiniões divergentes.

Nesse sentido, registramos que nos crimes contra a ordem tributária, principalmente quando não há pagamento de tributo ou repasse ao órgão previdenciário, por questões de dificuldades financeiras das empresas, quando 0 empregador concede preferência aos débitos trabalhistas, o Poder Judiciário vem acolhendo a tese explanada, para absolver os responsáveis pelos atos tributários de qualquer conduta criminosa.

Enfim, as dificuldades financeiras, em geral, fazem parte do dia a dia das pessoas físicas e jurídicas, e eventual ausência de norma legal quanto à exclusão da culpabilidade, não pode ser obstáculo à aplicação do princípio da inexigibilidade de conduta diversa, para uma efetiva aplicação da justiça, conforme anseios da sociedade brasileira, até porque trata-se de dever do Estado de Direito a distribuição da justiça. 


\section{REFERÊNCIAS}

AZULAY NETO, M. TRF $2^{\mathrm{a}}$ R. - ACr 2007.50.01.005153-5 - (6325) - $2^{\mathrm{a}}$ T. Esp. DJe, 19.12.2008.

BetTIOL, G. Direito Penal. São Paulo: Revista dos Tribunais, 1971.

BITTENCOURT, E. de M. Vítima. São Paulo: Leud, 13. ed., 1998.

CAMPOS, J. M. A Inexigibilidade de Outra Conduta. Belo Horizonte: Del Rey, 1998.

COSTA, A. M. da. Direito Penal. São Paulo: Forense, 1982.

FERRI, E. Princípios de Direito Criminal. São Paulo: Bookseller, 1996.

FRAGoso, H. C. Lições de Direito Penal. Rio de Janeiro: Editora Forense, 2004.

HUNGRIA, N. Direito Penal. 4. ed. Rio de Janeiro: Forense, 1958.

OLIVEIRA FILHO, M. de O. Temas Atuais de Advocacia Criminal. São Paulo: Etna, 1996.

GOMES, L. F. Erro de Tipo e Erros de Proibição. 3. ed. São Paulo: Revista dos Tribunais, 1996.

JESUS, D. E. de. Código Penal Anotado. 4. ed. São Paulo: Saraiva, 1994.

JESUS, D. E. de. Novas Questões Criminais. São Paulo: Saraiva, 1993.

LEAL, J. J. Curso de Direito Penal. Furb, 1991.

LUNA, E. da C. Estrutura Jurídica do Crime. 3. ed. Recife: Universidade Federal de. Pernambuco, 1970.
MAGALHÃES, D. Causas de Exclusão do Crime. 2. ed. São Paulo: Saraiva, 1975.

MARREY, A.; FRANCO, A. S.; STOCCO, R. Teoria e Prática do Júri. 5. ed. São Paulo: Revista dos Tribunais, 1993.

MIRABeTte, J. F. Manual do Direito Penal. São Paulo: Atlas, 6. ed., 1986.

MOREIRA, R. F. TRF $5^{\text {a }}$ R. - EINFACR 95.05.03026-6/01 - (4212/PB) - TP - DJE, 20.01.2009.

NUNES, L. A. R. Manual da Monografia Jurídica. São Paulo: Saraiva, 1997.

PEDRoso, F. de A. Direito Penal. São Paulo: Leud, 1993.

REY-LOPEZ, M. Crime. Rio de Janeiro: Artenova, 1973.

ROSA, A. J. M. F. Direito Penal. São Paulo: Revista dos Tribunais, 1995.

ROSA, F. B. da. Ac un da $1^{\underline{a}} T$ do TRT da $4^{\underline{a}}$ $R-A c n$ 98.04.03996-6-PR - 09.03.1999 , DJU 2 - 31.03.99.

SHECARIA, S. S.; JÚNIOR, A. C. Pena e Constituição. São Paulo: Revista dos Tribunais, 1995.

SOBRINHO, J. W. F. Repertório $I O B$ de Jurisprudência. São Paulo: 23/1995.

SYKES, G. M. Crime e Sociedade. Rio de Janeiro: Block, 1969.

TOLEDO, F. de A. Princípios Básicos de Direito Penal. São Paulo: Saraiva, 4. ed., 1991.

VELO, J. T. O Juízo de Censura Penal. Editor Sérgio Antônio Fabris. Porto Alegre, 1993. 